2017-03-27

\title{
Organizations as Open Systems That Need Purpose and Integrated Thinking
}

\author{
Hurth, V
}

http://hdl.handle.net/10026.1/9058

10.1002/bl.30069

Board Leadership

All content in PEARL is protected by copyright law. Author manuscripts are made available in accordance with publisher policies. Please cite only the published version using the details provided on the item record or document. In the absence of an open licence (e.g. Creative Commons), permissions for further reuse of content should be sought from the publisher or author. 


\title{
Organizations as Open Systems That Need Purpose and Integrated Thinking
}

\author{
Victoria Hurth
}

It is becoming impossible to sustain an isolationist view within organizations and many argue we need to completely revise the lens through which we view organizations in order to understand how to maximise performance (Wheatley 1999). Organizations must see themselves as part of dynamic environments that they affect and which affect them through rapid feedback as well as emergent, longer-term and unexpected consequences. Increasing complexity, recognising the importance and limits to the various capitals businesses rely on, and the increasing global consciousness requires organizations to view themselves within a system rather than isolates units that decide when and how to engage. Operating as members of a system requires that organizations are reflexive and clear about what they are trying to achieve in the system, why this is valuable, and who or what they ultimately rely within the system to achieve their goals. Integrated thinking and shifting to a purpose-driven organization are two ways organizations can systemically address the challenges faced and turn them into massive opportunity, however these shifts are profound and realising them rests heavily on governance.

\section{Why Organizations Must Relate to their Environment}

\section{The VUCA environment}

Organizations have never operated in a vacuum. However, we (particularly in Western thought) went through a period of time where we attempted to pretend that they could - or at least that we could contain and control organizational interactions with the outside world. This view of isolated organizations can be seen as strongly linked to the liberal 'scientific' approach of understanding the world by breaking things into smaller parts, which in effect serves to distance these parts, in our thinking, from the interconnected whole. Something documented by a range of authors from Capra 1997 to Checkland (1997) and in an organizational context examples include Senge (1990) and Hutchins (2014). This was arguably heightened in the 70s/80s/90s when the economic neoliberal era penetrated (Duit et al. 2010) when economics the normative way in which we allocate scare resources in order to maximise societal welfare (wellbeing), was largely reduced to a set of mathematical equations.

There have been many challenges to reductionism and its necessary assumptions we sold ourselves in order to cope with those aspects that didn't fit the 'model', and these have come from a range of disciplines e.g. psychology (Kahneman et al., 1982), international development 
(Stiglitz, 2010) and via postmodernist thinking (e.g. Featherstone, 1991). However, it is the inescapable reality of an increasingly complex and interconnected world that are perhaps at the heart of an observable rejection of this approach.

The notion that our world is becoming faster, more complex and more interconnected is a long talked about phenomenon. Some pinpoint a shift to seeing life as complex in the 1920's after the First World War and Bolshevik revolution, (Chandler, 2014). Others connect it to discovery of the 'uncertainty principle' in quantum mechanics which undermined the idea that science could predict the world with certainty (Mitchell, 2011). This has now taken shape in organizational language (a sign of concept maturity) in terms of what is known as a 'VUCA environment' (volatile, uncertain, complex and ambiguous). The reasons behind an increasing VUCA environment have been analysed over the years, with the key interrelated themes including rapid advancement of technology speeding up the creation and transfer of information and reaction to it, globalisation (the increased connection between organizations and their dependencies) and fragmentation (of identities, systems, preferences).

It is the 'chaos' that ensues that provides one of the foundational imperatives for organizations to primarily understand themselves within the context of their external environment and relationships with it. Despite attempts to run faster and study more individual facets more furiously, there are signs that those overseeing and studying organizations are moving instead towards a different way of conceiving of organizations - towards a systems view. It is this, sometimes subtle, shift towards systems thinking over the decades that could be judged as shifting organizational focus onto the relations between a system and its environmental context, rather than on the internal operations of the system (Luhmann, 1991).

From a systems view, organizations are seen in the context of a complex bounded planetary system. The organization is made up of many interdependent parts and one of many bounded sub-systems, which interact and have varying dependencies. This means that understanding the interactions and relationships between the whole and its parts, and between different interdependent systems in the environment, takes on great importance for understanding how that system works, how it can be influenced and how it can cope with chaos. This does not mean that reductionist thinking is replaced by considerations of the whole, but that dialogue between the two needs to occur (Mele, 2010).

\section{Limits to the way we regard and use capital}

As well as chaos providing a core motivation for whole scale perspective change, since the 70s, the planetary system has also been informing us, with greater and greater clarity, that we are reaching limits to the natural systems that provide the basis of all organizational functioning. 
This provides an additional core requirement for organizations to see themselves as part of a broader system, and the realities of living at the edge of these limits that are, in themselves, a driver of the VUCA environment, yet at the same time a driver of a far longer-term perspective in order to understand the system processes.

Recent estimates by the UN suggest that as a result of desertification and drought, 12 million hectares of arable land are lost per annum (23 hectares per minute), an area where 20 million tons of grain could have been grown; of 600 marine stock monitored by the UN, only $3 \%$ of global fish stock are underexploited; WWF estimate that we have lost $50 \%$ of wild animals in the past 40 years and although South Africa, Brazil, the USA and China have all grown their GDP in 1990-2008, they have have significantly depleted their natural capital reserves over the same period by $33 \%, 25 \%, 20 \%$ and $17 \%$ respectively. One of the key drivers of this is that organizations, who are those that are the key decision makers in resource use, pay only a small percentage of the real cost of natural resources if they were to be preserved in a system state that can perpetuate itself. If this full cost was accounted for, KPMG estimate that this would, on average, wipe $41 \%$ off organisational earnings (KPMG, 2012).

Of course it is not just natural capital that has been unfairly and unsustainably exploited, with human and social/relational capital (depending on who you are and where you live), also paying a price of the modus operandi of many organizations. This may be because of the unethical practices hidden within a supply chain or more intractably, because of the system impacts of the exploitation of natural resources - for example the use of palm oil or similar products which create disastrous knock-on system effects. It is not just for-profits that are at fault here, with non-profits also often just as culpable of 'Robbing Peter to Pay Paul', or worse. As demonstration of how difficult the move to systems thinking is, the obvious interconnection between the natural and human systems has only in recent years started to be communally expressed by NGOs operating on each side of the 'fence'. The point being that we are only just starting to connect the dots between different systems and their interdependencies and there are very few organizations that are accountable for all their value creation and value destruction.

\section{The evolution of consciousness}

A third key strand that is feeding the shift to organizations broadening and deepening their selfperspective, is that of evolutionary global consciousness. Academics pinpoint the dawning of instant communications as the basis required for global consciousness which since the middle of the last century (the Information/knowledge age) has exploded in its capacity and accessibility (Banathy, 1998). We have been on a journey of ever widening space/time consciousness and this allows us to see global humanity and our shared dependencies within a 
planetary system - an increasing system-wide global consciousness. This exposes mutually dependant relationships between organizations and their broad stakeholders. The system awareness by stakeholders has resulted in claims on the organization from an increasing range of groups (Bundy, et al. 2012), as they become more and more aware of the impact on their lives (or of their offspring) of the decisions that organizations make in terms of how they utilise resources and add or destroy value. This includes employees and customers who are increasingly seeking meaning from what they do and buy. The deeper understanding and relationships that are emerging between an organization and its stakeholders underpins a stronger ethical imperative for an organization to understand its impacts, minimise negatives and maximise the positives. Instantaneous global knowledge sharing has also impacted the shift to ethical approaches to stakeholders through the impossibility of gatekeeping knowledge - PR departments can no longer decide how an organization appears. An unethical culture therefore poses huge unmanageable risks and many organizations are attempting a turn to genuine transparency as the only practicable way forward. The potential for this authentic ethical imperative to be not just a hygiene factor, but the backbone of a highly motivated workforce and engaged stakeholders is just starting to be really interrogated, and will be addressed below.

\section{How Organizations Must Relate to their Environment}

The above represents some of the key drivers for organizations to regard themselves as an intricate part of a complex system rather than an isolated entity that decides when and how to engage. Although a shift can be discerned over the past few decades, we are only on the cusp of understanding what this means for the way we govern organizations and how these changes can be implemented.

Much has been written, from a range of perspectives on how organizations can address the discrete drivers outlined above, but, in recent years, systemic approaches commensurate with the challenge and opportunity posed are beginning to emerge in mainstream organizational language and behaviour.

\section{Integrated Thinking}

One way organizations have started to better relate to their environment is through the adoption of 'integrated thinking' a term which is becoming widely use and which could be seen as another term for systems thinking. This is strongly associated with the Integrated Reporting Council and their global framework for reporting which they launched in 2014 as a replacement for standard financial reporting, and is already obligatory in some countries, such as South Africa. IR requires organisations to report on: their short, medium and long-term value creation 
strategy; the capitals required to deliver it; the material risks to those capital as well as assessment of how they will enhance rather than deplete them and the governance structures that will oversee the delivery. The report therefore demands an organization to understand itself and its relation to the 'system' in much more depth and to prove to itself, investors and other stakeholders that it is truly a value creation entity. Drawing from the Daly Triangle, an organization must as a result, begin to think about the ultimate ends it is trying to create and the ultimate means on which it depends to do this (Daly, 1973), and all the interactions in between - rather than continuing to focus on narrow instrumental ends and instrumental ends. It is ultimately for boards to decide to adopt this approach and by doing so they will likely be initiating a deep journey of self-reflection and systemic change, as those who have undertaken this journey testify.

\section{Organisational purpose}

Integrated reporting gets organizations to ask the right questions of a business but doesn't specifically address an approach to dealing with the multiple crisis of VUCA, sustainability and the search for activities we can be meaningfully proud of. Perhaps the most significant advance is in this area is the notion of organizational 'purpose' which is being advanced across a range of organizational forms, including publically listed for-profits. Although there is still concept ambiguity, purpose is about an organization being clear about its long-term fundamental societal reason for existence - its core service group, the long-term positive outcomes it wants to see for them, its particular organizational role in achieving this and the way in which it will serve the long-term interests of its stakeholders within the system who underpin the delivery of those outcomes. Because the overarching frame is about high-level, long-term societal good, this necessitates an organization to think systemically - and again to connect these ultimate ends to ultimate means. To deliver the outcomes most successfully, and sustainably, requires recognising the intricacies of the system that influences these outcomes and working with this system creatively and flexibly to achieve the best results, in a financially and resource sustainable way.

As a systems concept, purpose offers a way of dealing with chaos. Traditionally chaos was seen as needing to be evaded through control, however, as Dolan and Garcia note, there is "there's such a tight relation between chaos and order, so much that one leads to another in a dynamic process. You don't try to avoid chaos, instead you use it to self-organise your system through an 'attractor'. Purpose could be seen as providing a clear transcendent societal attractor which provides the common force that unites the energy and objectives of the organization and its stakeholders. The existence of a meaningful reason for productive efforts by employees also means that energy is enhanced, because the motivation to achieve organizational ends is increased. For example, being clear about the ultimate reason for people's work is shown to 
increase performance (Carton et al., 2014). This is further enhanced because the existence of a clear context for decision making allows for a reduction in management rules, instructions and objectives and instead unleashes the creativity, passion and agility of employees.

Therefore, purpose appears to offer the potential to make organizations more agile and entrepreneurial and more empowering, challenging and meaningful for employees - the most significant resource in most organizations. Additionally, through an absolute focus on the 'who' they serve and a clarity of organizational identity that is meaningful at a human level, the organization is much more likely to harness the energy of stakeholders and create highly satisfied and loyal customers. More profoundly still, it offers the opportunities for organizations to create real net value for society through innovation and business model design which serves society.

Purpose is not just about having a higher-goal but it is about how this is expressed and lived out daily and in relation to the system as a whole - it is DNA level. Shifting to a purpose-driven organization is a huge undertaking, with many on this journey saying that you either need to be committed for the long hard road or wait until you are. Therefore, it could arguable be seen as an equal challenge (and opportunity) to social enterprises, B-Corps and third sector organizations, whose constitutional declaration of social purpose and supportive owners may aid this but do not determine it.

Setting, communicating and delivering an organization's purpose is at the heart of governance. This poses a fundamental challenge to governance if the long-term interest of the organization (both as a system member and due to its interconnection with the rest of the system) is best delivered through service to a higher societal purpose, and yet the owners of the organization do not recognise this (or do not have the long-term interests of the business at heart but rather short term monetary gain at the expense of this). The governing body therefore has a vital role, not just to distil the purpose, and support the executive to create a purpose-driven organization, but it also has a significant responsibly to influence owners to make sure that the overarching purpose is shared. If not, then this represents perhaps the ultimate conflict of interest.

Supporting this shift, it is important to recognise that owners are also subject to the same forces outlined earlier in the paper. The economy is, at its core, about allocating scare resources to maximise social welfare/wellbeing. Organizations are given the social license to operate because they are entrusted with our shared planetary and national capital to transform it in a way that serves us best. This is the reality that overarches any ownership structure - 
something that has been brought to the fore in recent years, with trust in organizations at an all-time low as the social contract has been broken time after time.

In conclusion, organizations are facing a range of pressures which fundamentally alter how they need to perceive themselves within their environment in order to provide the conditions for organizational success. A systems view is required and within this, a new way of viewing their role within that system. Integrated thinking and organizational purpose offer two, aligned, approaches that organizations can adopt to transform themselves. Both require seeking real long-term value creation for society as the core goal - above any short-term demands of owners or other stakeholders.

\section{References}

Banathy, B.H. (1998) 'Evolution guided by design: A systems perspective'. Systems Research and Behavioral Science, 15(3), pp. 161-172.

Bundy, J., Shropshire, C. and Buchholtz, A.K. (2012) 'Strategic Cognition and issue Salience: Toward an explanation of firm responsiveness to Stakeholder concerns', Academy of Management Review, 38(3), pp. 352-376.

Carton, A., Murphy, C., \& Clark, J. 2014. A (blurry) vision of the future: How leader rhetoric about ultimate goals influences performance. Academy of Management Journal, 57: 1544-1570

Capra, F. 1997. The web of life. New York: Doubleday-Anchor Book.

Chandler, D. (2014) 'Beyond neoliberalism: Resilience, the new art of governing complexity', Resilience, 2(1), pp. 47-63

Checkland, P. 1997. Systems Thinking, Systems Practice. Chichester: John Wiley \& Sons Ltd.

Daly, Herman E., ed. (1973). Toward a Steady-state Economy. San Francisco: W.H. Freeman.

Duit, A., Galaz, V., Eckerberg, K. and Ebbesson, J. (2010) 'Governance, complexity, and resilience', Global Environmental Change, 20(3), pp. 363-368.

Featherstone M. (1991). Consumer Culture and Postmodernism. Sage: London. 
Hutchins , G. (2014). The Illusion of Separation: Exploring the Cause of Our Current Crises. Floris Books, UK.

Kahneman, D., Slovic, P., and Tversky, A. (1982). Judgment under uncertainty: Heuristics and biases. Cambridge. Cambridge University Press.

KPMG (2012) Expect the Unexpected: Building Business Value in a Changing World. KPMG

Luhmann N. (1991) The cognitive program of constructivism and a reality that remains unknown. In: Krohn W., Küpper G. \& Nowotny H. (eds.) Selforganization. Portrait of a scientific revolution. Kluwer, Dordrecht: 64-85.

Mele, C., Pels, J. and Polese, F. (2010) A Brief Review of Systems Theories and Their Managerial Applications. Service Science 2(1-2):126-135.

Mitchell, M. (2011) Complexity: A guided tour. Oxford: Oxford University Press

Senge, P.M. 1990. The Fifth Discipline, The Art and Practice of the Learning Organization. New York: Doubleyday

Stiglitz, J. E. (2010). Freefall: America, free markets, and the sinking of the world economy. NY. W.W. Norton and Co

Wheatley, M.J. (2001) Leadership and the new science: Discovering order in a chaotic world. 2nd edn. San Francisco, CA: Berrett-Koehler. 